\section{The Effect of Year and Irrigation on the Yield Quantity and Quality of the Potato}

\author{
Éva Babett Ábrahám - Eszter Zsom - \\ Mihály Sárvári \\ University of Debrecen, Centre for Agricultural Sciences, \\ Faculty of Agricultural Sciences, \\ Department of Crop Production and Applied Ecology, Debrecen \\ abrahameva@dateki.hu
}

\section{SUMMARY}

In Hungary, the growing area of potato area reduced dramatically in the last few decades, additionally we are lagging behind the Western European countries as regards yields and the competitiveness of production is further decreased by the great alternation in yields from year to year, the unpredictable market conditions, bad consumption habits and many times unfortunately the lack of quality products.

The ecological and climatic conditions of Hungary are not everywhere suitable for potato, in the area of Debrecen the amount of rainfall was lower, and the monthly average temperature was higher than the requirement of potato in its growing season in 2002 and 2003.

The experiment was carried out at the experimental site of the University of Debrecen, Farm and Regional Research Institute, at Látókép. In our experiment we examined the yield and some quality parameters of 8 and 9 medium-early varieties in large parcels in 2002 and 2003 respectively. Out of the examined varieties 3 are of Dutch, and 6 are of Hungarian breeding.

The experiment was set up on $49.5 \mathrm{~m}^{2}$ parcels on calcareous chernozem soil after winter wheat as a forecrop in both years. The 9 varieties were examined in 4 repetitions in randomized blocks, out of which two repetitions were irrigated, and two were nonirrigated.

We examined the yields of the varieties, the distribution of tubers according to size and their percentages, and the changes in specific parameters of quality and inner content due to irrigation. We studied the dry matter content, the starch content, the underwater mass, the amount of reducing sugars, the colour index of frying and the element contents of tubers.

Summing up, it can be stated that among the agrotechnical year effect, variety and irrigation factors have considerable impact on potato yield quality and quantity. On the basis of our results, it can be stated that in potato production variety should be chosen in accordance with the aim of production and technology should be adapted to that specific variety.

Keywords: potato, varieties, irrigation, quality

\section{INTRODUCTION}

In Hungary, the growing area of potato has reduced dramatically in the last few decades, and production is lagging behind Western European countries as regards yields. Competitiveness is further decreased by the great alternation in yields from year to year, unpredictable market conditions, poor consumption habits and many times the lack of quality products. Our opportunities are hindered by the application of out-of date technologies.

The ecological and climatic conditions of
Hungary are not uniformly suitable for the potato (Sárvári, 2001). For the potato - considering its place of origin - humid areas are the most suitable, where the weather is slightly cool, and the summer is moderately worm (Mészáros, 1979). The high temperature reduce the allocation of plant biomass to tubers and will cause smaller leaves, more nodes per stem, longer internodes, taller plamts, higher leaf areas, and lower rations of leaf/stem leaf (Khedher and Ewing, 1985). Water stress causes reduction of yield by reducing growth of crop canopy and biomass. Water at 3-5 mm per day is necessary for evapotranspiration (ET) and maintenance of optimal soil moisture tension $(10-50 \mathrm{kPa})$ in growing potatoes (Marutani and Cruz, 1989). In order to maintain at least our domestic market positions - even after EU admission - we should improve the level of production. To achieve this, quality should improve with an enhancement of yield per hectare and a simultaneous reduction of production costs (Kruppa and Zsom, 2001).

\section{METHODS}

Ecological conditions were unfavourable for the potato in 2002 and 2003. In 2002, the amount of precipitation was $308 \mathrm{~mm}$ between April and September, and in 2003, the quantity of rainfall was $219 \mathrm{~mm}, 120 \mathrm{~mm}$ lower than the average rainfall of the last 30 years in the vegetation period of potato. The average temperature was higher than that of the last 30 years in most months both in 2002 and 2003. The average daily temperature was $19-22^{\circ} \mathrm{C}$ in these months, while the requirement of the potato is 17 $19^{\circ} \mathrm{C}$. The droughty weather influenced the development of the tubers disadvantageously.

The experiment was carried out at the experimental site of the University of Debrecen, Farm and Regional Research Institute, at Látókép. In our experiment, we examined the yield and several quality parameters of 8 and 9 medium-early varieties in large parcels, in 2002 and 2003, respectively. Of the examined varieties, the Kondor, Kuroda and Desirée are of Dutch, while the Százszorszép, Góliát, Kánkán, Hópehely, White Lady and Lilla are of Hungarian origin.

The experiment was set up on $49,5 \mathrm{~m}^{2}$ parcels on calcareous chernozem soil after, winter wheat as a forecrop. The varieties were examined in 4 repetitions in randomized blocks, of which two repetitions were irrigated, and two were nonirrigated. The applied chemical fertilizer agent per 
hectare was $165 \mathrm{~kg}$ from $\mathrm{N}, 120 \mathrm{~kg}$ from $\mathrm{P}_{2} \mathrm{O}_{5}, 220$ $\mathrm{kg}$ from $\mathrm{K}_{2} \mathrm{O}$. The irrigated repetitions were irrigated 4 times. In 2002, we irrigated with $40 \mathrm{~mm}$, and in 2003 with $30 \mathrm{~mm}$ water norm.

\section{RESULTS}

In 2002 (Figure 1), the yield ranged between 20$30 \mathrm{t} \mathrm{ha}^{-1}$ without irrigation. As a result of irrigation, the yield $c v$. White Lady, cv. Desirée, cv. Kondor and cv. Kuroda exceeded 50 t/ha. 2003 was a very draughty year, and its effect was obvious in the yields. In 2003 (Figure 2), without irrigation, yields ranged between 13.71 (Százszorszép) and $24.35 \mathrm{t} / \mathrm{ha}$ (White Lady) depending on the variety. The differences between the varieties in their response to irrigation were obvious. As a result of irrigation, yield increased by $66 \%$ in the average of the 9 varieties. Under irrigation, the yield of cv. Desirée was the lowest with $28.6 \mathrm{t} / \mathrm{ha}$, and only the yield of cv. Kondor was higher than $40 \mathrm{t} / \mathrm{ha}$.
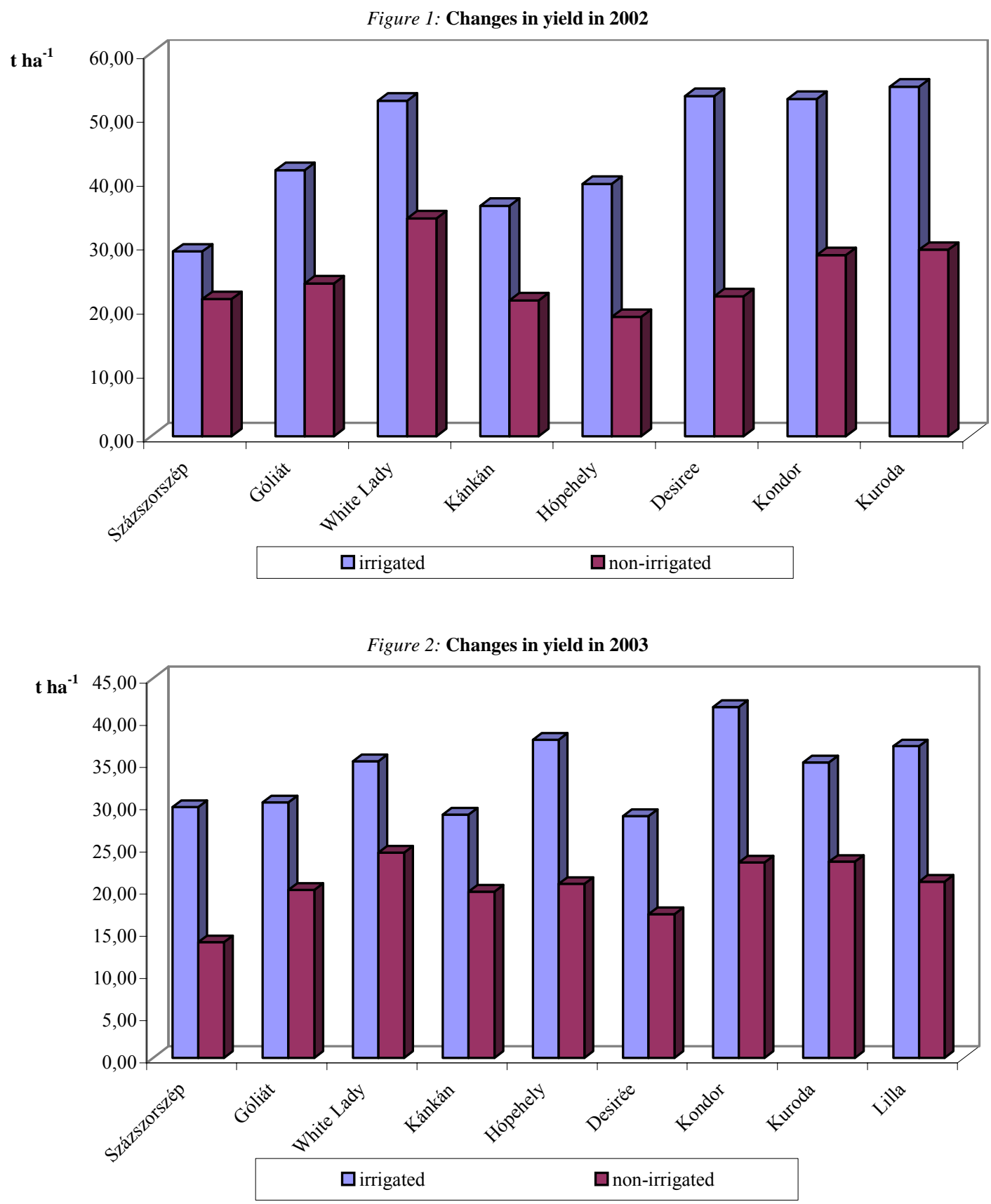

In 2002, the dry matter content of $c v$. Kondor was the lowest both under irrigated (16.55\%) and under non-irrigated (14.7\%) treatments (Figure 3). As a result of irrigation, the dry matter content of $c v$.
Kondor and $c v$. Desirée increased by 12.5 and $14.5 \%$. The dry matter contents of $c v$. Kuroda and $c v$. Százszorszép were the most favourable, the dry matter content of these varieties was around $20 \%$ 
both under irrigation and without irrigation. In 2003 (Figure 4), the dry matter content of cv. Lilla was the lowest $(18.57 \%)$, and the dry matter of cv. White Lady content was $25.6 \%$ without irrigation. Under irrigation, the dry matter content increased in most of the varieties, but the dry matter content of $c v$. White Lady decreased by $2.43 \%$. The dry matter content of cv. Kánkán increased by the largest amount (2.74\%), due to irrigation $\left(\mathrm{SD}_{5 \%}=2.71\right.$ between the varieties).

Figure 3: Changes of dry matter content in $\mathbf{2 0 0 2}$

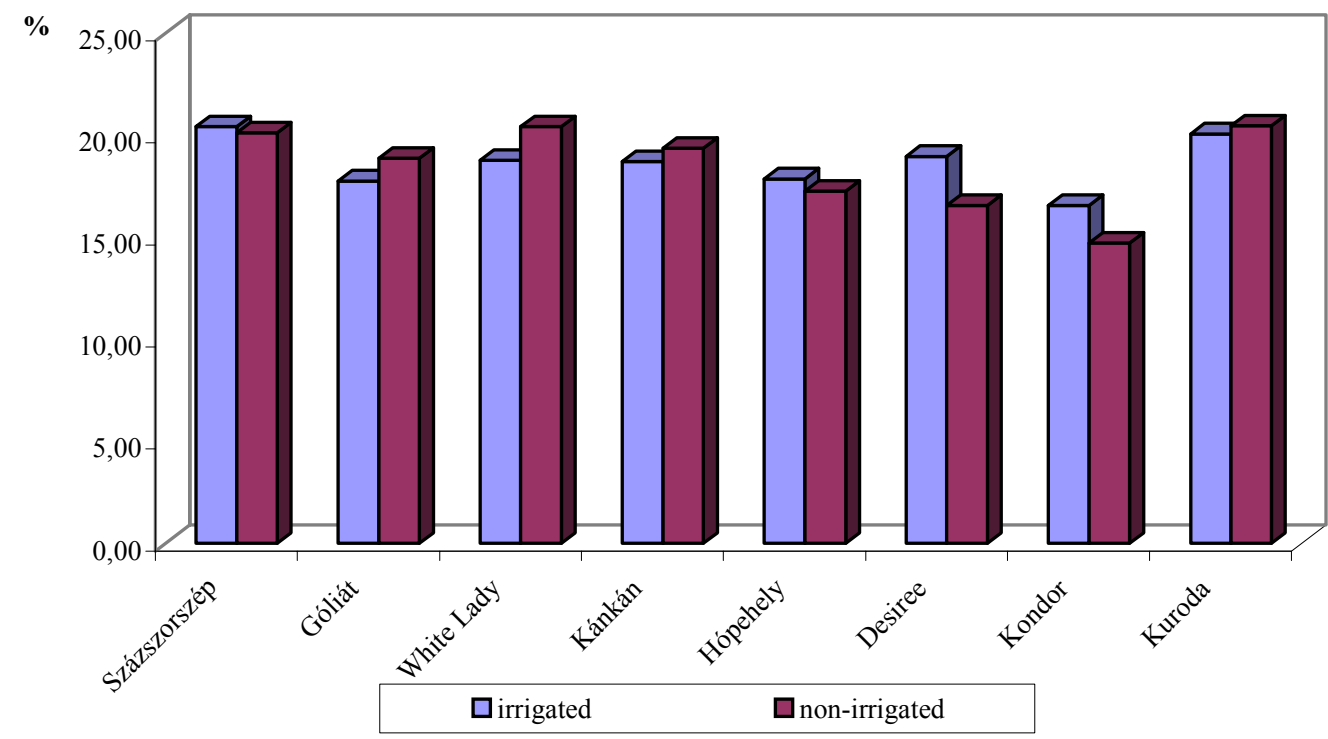

Figure 4: Changes of dry matter content in 2003

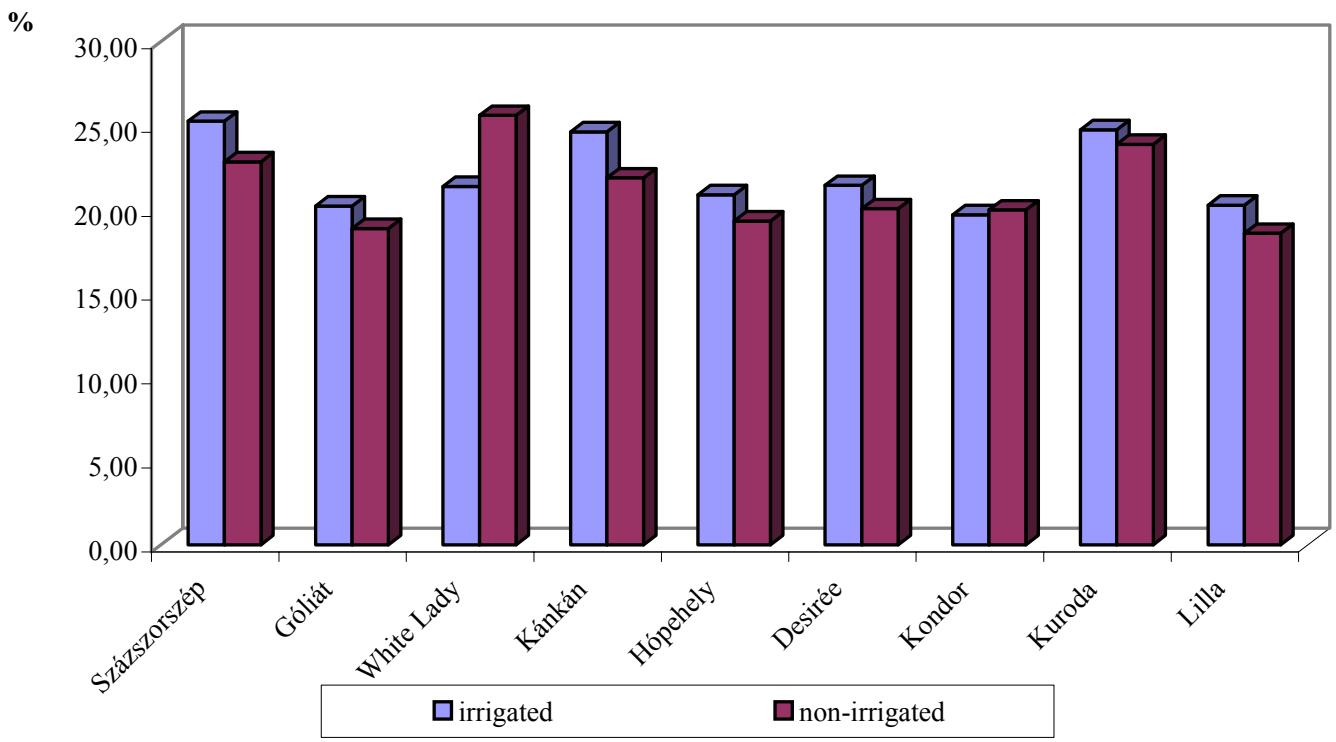

The index of frying colour is important in the respect of the consumption, in order to make chips or fried potatoes. If this value is high, the colour of the chips or the fried potatoes will become brown, and their taste will be unpleasant. In this experiment, in 2002 (Figure 5), the indices of cv. Százszorszép and $c v$. Góliát were the lowest, while the indices of $c v$. Kondor and cv. Hópehely were unfavourable. In 2003 (Figure 6), the colour indices of cv. Kánkán,
Százszorszép and Kuroda were the lowest, and this value was high for $c v$. Lilla, White Lady and Hópehely. Irrigation had an advantageous effect on colour index in most of the varieties. The index of cv. Százszorszép decreased by the highest value. The change in the colour index due to irrigation of cv. Kondor and Kuroda was unfavourable, because in the case of these varieties, this value increased $\left(\mathrm{SD}_{5 \%}=2.92\right)$. 
Figure 5: Changes of colour index in 2002
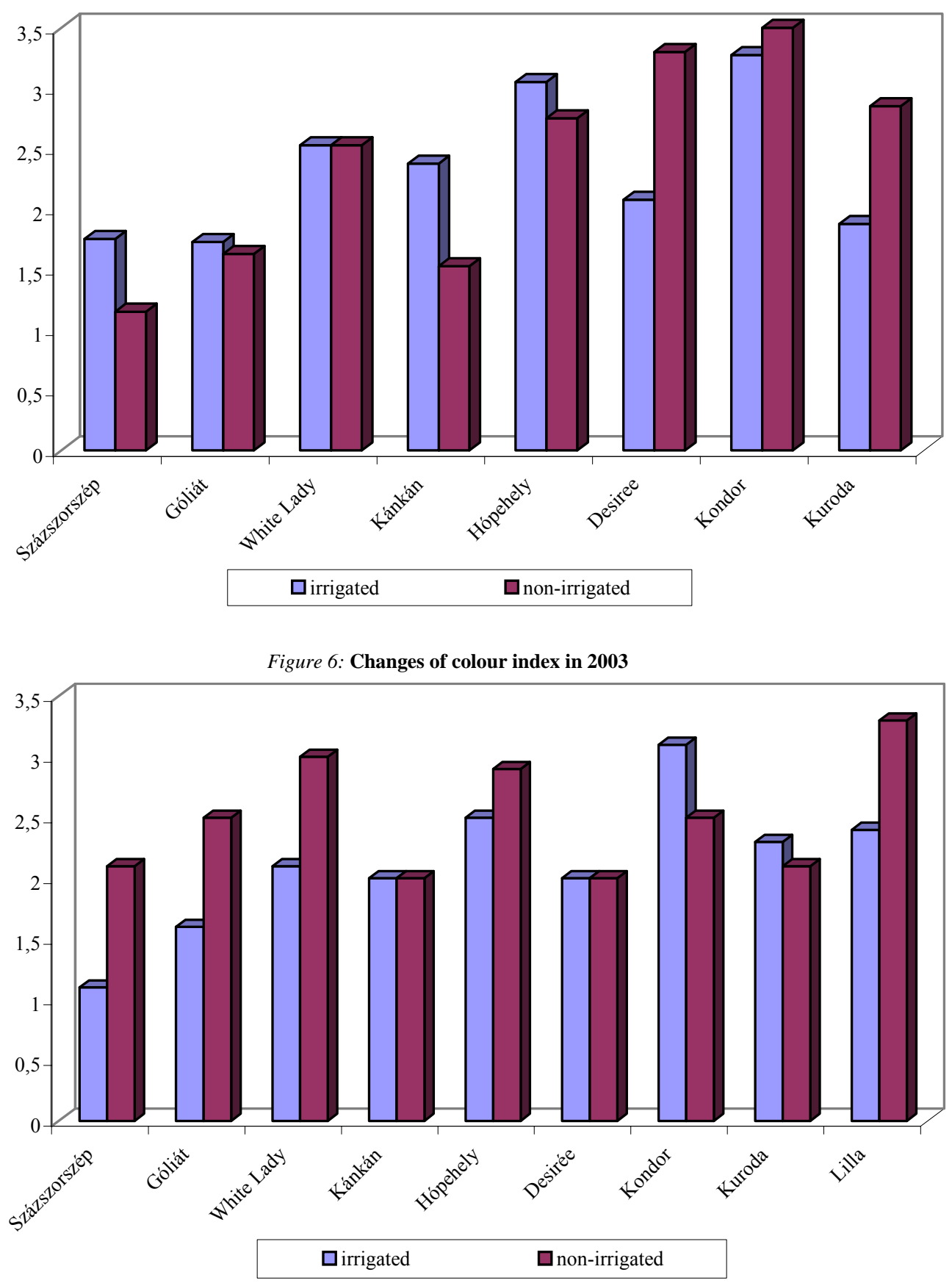

\section{CONCLUSIONS}

On the basis of our results, it can be stated that irrigation has significant effects on the quality and quantity of potato. With expert irrigation, the yield and the quality of potato can be improved. The improvement of the competitiveness of potato production and the enhancement of technology can be achieved by increasing irrigation, by growing modern resistant varieties which have high yield capacities and high biological values. In potato production, variety should be chosen in accordance with the aim of production and technology should be adapted to that specific variety. 


\section{REFERENCES}

Bacsó, N. (1966): Szempontok a burgonyatermesztéshez. Agrofórum, Budapest

Khedher, B.-Ewing, E. E. (1985): Growth analyses of eleven potato cultivars grown in the greenhouse under long photoperiods with and without heat stress. American potato journal, 62. 537-554

Kruppa, J.-Zsom, E. (2001): The effect of potassium fertilization on potato yield quality and quantity. In: Fertilizers in context with resource management in agriculture. Volume II. 664-670.

Marutani, M.-Cruz, F. (1989): Influence of supplemental irrigation on development of potatoes in the tropics. Hort Science, 24. 6. 920-923.

Mészáros, F. (1979): A burgonya termesztése. Mezőgazdasági Kiadó, Budapest

Sárvári, M. (2001): A termesztési tényezők hatása a burgonya termésére. In: Burgonyatermesztés, 21. 